\title{
Oxidative stability of the salad dressing enriched by microencapsulated phenolic extracts from cold-pressed grape and pomegranate seed oil by-products evaluated using OXITEST
}

\author{
Fatma Sema AKSOY ${ }^{1}$, Zeynep Hazal TEKIN-CAKMAK ${ }^{1 *}$ (D), Salih KARASU ${ }^{1}$, Ayse Semra AKSOY ${ }^{1}$
}

\begin{abstract}
This study aimed to investigate the potential use of cold-pressed pomegranate seed oil by-product (PGOB) and grape seed oil by-product (GOB) as a natural antioxidant in a salad dressing. Firstly, bioactive compounds from oil by-product were extracted and powdered by spray drier to produced grape seed oil by-product powder (GOBP) and pomegranate seed oil by-product powder (PGOBP). This study was the first attempt to evaluate the oxidative stability of the salad dressing by OXITEST at 90 , 100 , and $110^{\circ} \mathrm{C}$, and at 6 bar (the oxygen pressure). The samples enriched by GOB (3.22-26.76h) and PGOB (2.49-24.76h) showed high IP compared to control samples $(0.43-8.82 \mathrm{~h})$. The oxidation rate was modeled by zero, first and second-order kinetic models, and the oxidation kinetics constant $(\mathrm{k})$ value estimated. PGOBP and GOBP significantly reduced $\mathrm{k}$ value. The activation enthalpy $\left(\Delta \mathrm{H}^{++}\right)$, activation entropy $\left(\Delta \mathrm{S}^{++}\right)$and activation energy $\left(\mathrm{E}_{\mathrm{a}}\right)$ were $69.78-101.93 \mathrm{~kJ} / \mathrm{mol}, 59.55-81.07 \mathrm{~J} / \mathrm{mol}$ and (-18.36)-(-83.37) J/mol respectively. The $\Delta \mathrm{G}^{++}$of the control, PGOBP and GOBP enriched samples were 87.36-88.10 Kj/mol, $88.65-91.61 \mathrm{Kj} / \mathrm{mol}$, and $88.14-91.48 \mathrm{~kJ} / \mathrm{mol}$ respectively. This study suggests that PGOBP and GOBP could be used as a natural antioxidant source for salad dressings.
\end{abstract}

Keywords: by-products; natural antioxidant; oxidation kinetics; OXITEST.

Practical Application: The oxidation kinetics of the salad dressing typed emulsion.

\section{Introduction}

Salad dressings type emulsions have more than $30 \%$ vegetable oil with a high level of unsaturated fatty acids. Oxidation is the main deterioration reaction determining the shelf life of the emulsions containing a high level of unsaturated fatty acid. The shelf life of the salad dressing type emulsions ranges from 6 to 12 months at room temperature and can be increased by retarding of oxidation. The primary method of the retarding of oxidation and increasing shelf life is the addition of antioxidants. However, the majority of antioxidant substances currently used are synthetic materials having harmful potentials to human health. For this reason, in recent years, consumer preference has been shifted to natural sources of antioxidants instead of synthetic ones (Ghorbani Gorji et al., 2016).

By-products obtained from the cold-pressed oil industry can be considered as a potential source of food ingredients due to containing high protein, phenolics, and carbohydrate without any solvent trace (Aydeniz et al., 2014). Since GOB and PGOB are obtained by the processes without heat treatment and solvent extraction, they are rich in bioactive components with antioxidant properties (Karaman et al., 2015). Also, the solubility of these components in water and their potential for use in aqueous extracts will allow these materials to be used in many food formulations. Numerous publications have been conducted on the bioactive compound and antioxidant capacity of grape seed, and pomegranate seed (Shinagawa et al., 2015;
Wang et al., 2004; Yoshime et al., 2019). However, limited studies have been performed about GOB and PGOB. No attempt has been made on the evaluation of $\mathrm{PGOB}$ as a natural antioxidant in a salad dressing.

Many methods are used to evaluate the oxidation stability of salad dressing like emulsions. Most of these methods aim to test primary (hydroperoxides) and secondary oxidation products (aldehydes, and ketones) formed during the storage period (Caruso et al., 2017). However, these techniques, timeconsuming, expertise required, involve the use of toxic reagents, and expensive (Anwar et al., 2003). Therefore accelerated oxidation methods should be used instead of these methods.

As an accelerated oxidation test, OXITEST and Rancimat are the most used methods to measure the oxidative stability of fats in a short period without using expensive and toxic reagents (Tinello et al., 2018). From these methods, the rancimat can successfully evaluate the oxidative stability of the various fat-derived products by recording water conductivity, which rises as a result of the volatiles formation under constant high temperature and a certain atmospheric pressures (Anwar et al., 2003; Tinello et al., 2018). However, the rancimat method requires pretreatments methods such as fat/oil extraction. The OXITEST can test the oxidative stability of both raw materials and finished products without fat/oil extraction before analysis. OXITEST is 
based on the recording of oxygen pressure in analytical chambers where the sample is exposed to high temperatures (Caruso et al., 2017). Limited studies have been conducted on evaluating the oxidative stability of food products by OXITEST (Amato et al., 2015; Caruso et al., 2017; Patrizia et al., 2009).

This study aims to investigate the potential use of GOB and PGOB in a salad dressing as a natural antioxidant and to evaluate the oxidation stability of the salad dressing by OXITEST.

\section{Materials and methods}

In this study, GOB and PGOB were obtained from ONEVA Food Company (Esenyurt, Istanbul). After the cold pressing of pomegranate and grape seed, the obtained GOB and PGOB were finely ground and brought to Yildiz Technical University Food Engineering Laboratory. After grinding, the by-products were stored in a closed in a lightfree polypropylene bags at low temperature $\left(10^{\circ} \mathrm{C}\right)$ until their analysis. The moisture contents of GOB and PGOB were $5.52 \%$ and $4.56 \%$ respectively.

The study consist of four parts; (1) phenolic characterization of GOB and PGOB; (2) extraction of the antioxidant compounds from PGOB and GOB; (3) microencapsulation of the GOB and PGOB extracts; (4) investigation of the effects of the enriching of microcapsules on oxidative stability of salad dressing by OXITEST.

\subsection{Bioactive properties of the by-products (PGOB and GOB)}

\section{Extraction procedures}

The extraction of bioactive compounds from PGOB and GOB was performed according to the method described by Karaman et al. (2015). In brief, $500 \mathrm{~g}$ of the purified water-methanol mix (1/1) was added to 50 grams of each PGOB and GOB to adjust the liquid/solid ratio as 10 . Then, the extraction process was started for 2 hours on a rinsing water bath at $25^{\circ} \mathrm{C}$. After the extraction process; the extracts were transferred to $50 \mathrm{~mL}$ centrifuge tubes and centrifuged at $9000 \mathrm{rpm}$ for 10 minutes at $4{ }^{\circ} \mathrm{C}$. After centrifugation, the supernatant was collected and filtered by $0.25 \mu \mathrm{m}$ filters. The obtained extracts were held in a tightly closed glass at $4{ }^{\circ} \mathrm{C}$ until their analysis.

\section{Total Phenolic Content (TPC) determination}

A colorimetric method with Folin Ciocalteu's reagent was used for total phenolic content determination according to a procedure described by Singleton \& Rossi (1965). Firstly, Folin-Ciocalteu's reagent $(2 \mathrm{~N})$ was diluted ten times with distilled water to prepare the dilute solution $(0.2 \mathrm{~N})$. The $0.5 \mathrm{~mL}$ of extract was added to the centrifuge tube and mixed with $2.5 \mathrm{~mL}$ of diluted the reagent and two $\mathrm{mL}$ of sodium carbonate $(7.5 \%)$. The obtained mixture was subjected to an effective mixing with vortex and allowed to stand at room temperature for 30 minutes before measuring the absorbance at $760 \mathrm{~nm}$ by UV-VIS spectrophotometer (Shimadzu UV-1800, Japan). This procedure was repeated in triplicate for each sample. The total phenolic content was calculated and reported as gallic acid equivalents (GEA) in mg per kg PGOB and GOB sample.

\section{Determination of antioxidant activity}

The antioxidant capacity of PGOB and GOB was determined according to DPPH (1,1-diphenyl-2-picrylhydrazyl) free radical scavenging activity method (Prior et al., 2005). The $0.5 \mathrm{~mL}$ of methanolic extract was added to the DPPH radical solution prepared in $5 \mathrm{~mL}$ of methanol and then mixed by using vortex for an effective mixing process. The resulting mixture was allowed to stand in a dark place at room temperature for 30 minutes.

After the incubation, the samples were placed in glass cuvettes, and the absorbance at $515 \mathrm{~nm}$ was measured by using a UV/ VIS spectrophotometer (Shimadzu UV-1800, Japan). The pure methanol was used as the control sample. This procedure was repeated in triplicate for each sample. The antioxidant activity value of the extracts was estimated regarding $\% \mathrm{DPPH}$ inhibition using the following Equation 1:

$\%$ DPPH inhibition $=\frac{A c-A s}{A c} \times 100$

where Ac is the absorbance of the control and As is the absorbance of the samples.

\section{Determination of the phenolic profile of the by-product extract}

The phenolic composition of the extract was determined according to the method described by Karaman et al. (2015). HPLC system (Shimadzu, Kyoto, Japan) equipped with a DGU20A5 degasser, an LC-20AT gradient pump, a SIL-20A autosampler, a CTO-10A5 VP column oven, and an SPD-M20A diode array detection (DAD) system was used for the analysis of the phenolic profile. The column $(5 \mu \mathrm{m}, \mathrm{C} 18100 \mathrm{~A}(250 \times 4.6 \mathrm{~mm})$ from Phenomenex (Torrance, CA, USA) temperature was adjusted to $25^{\circ} \mathrm{C} .2 \%(\mathrm{v} / \mathrm{v})$ acetic acid was prepared in double-distilled water for mobile phase A; eluent B was $0.5 \%$ acetic acid in double-distilled water and acetonitrile $(50: 50, \mathrm{v} / \mathrm{v})$. The gradient was as follows: from 90 to $55 \%$ of A within $40 \mathrm{~min}$, from 55 to $0 \%$ of A within $5 \mathrm{~min}$, and returning to the initial $90 \%$ A within $5 \mathrm{~min}$. Between each analysis, $15 \mathrm{~min}$ of equilibration treatment (90\% of A) was performed. The flow rate was adjusted to $1 \mathrm{~mL}$ $\min ^{-1}$, and the injection volume was $20 \mu \mathrm{L}$.

\section{Encapsulation of phenolic extract}

Firstly, maltodextrin the percentage of $3 \%$ was added to $200 \mathrm{~mL}$ of phenolic extracts to achieve the ratio of the wall material and core material $1: 1$ and stirred at room temperature for $2 \mathrm{~h}$ to form the complete hydration. Then, the mixture was homogenized with Ultra Turaxta (IKA, Germany) at $10000 \mathrm{rpm}$ and 2 minutes for dissolution of maltodextrin in the extract. The extracts with maltodextrin were dried in a spray drier (Büchi Mini Spray Dryer B-290, Sweden) at a temperature of $180^{\circ} \mathrm{C}$. PGOBP and GOBP were collected and packed in polyethylene bags and stored in a freezer at $(-20)^{\circ} \mathrm{C}$ until analysis.

\section{Determination of particle size and particle morphology}

Particle size and morphology were characterized by using Scanning Electron Microscope (SEM) (FEI QUANTA FEG 250, 
$A B D)$. Morphological characteristics and average particle size of the capsules are evaluated by microscopy images.

\section{Preparation of the salad dressing samples}

The salad dressing samples were prepared according to procedures described by Akcicek \& Karasu (2018). First, xanthan gum was slowly added to the aqueous solution (vinegar and deionized water mix) and heated to $80{ }^{\circ} \mathrm{C}$ for $20 \mathrm{~min}$ to obtain complete hydration. After cooling the solution to room temperature, egg yolk (3\%), salt (1\%), and sugar (5\%) were added to the xanthan gum solution. After dissolving the xanthan gum and other ingredients, stirring was continued at $1,000 \mathrm{rpm}$ in a magnetic stirrer for a period of $6 \mathrm{~h}$ to complete the hydration of the mix. Finally, corn oil (20\%) was added to the mix, and homogenization for 3 min by Ultra Turraks (Daihan, HG-15D) at 10,000 rpm was conducted to form an emulsion. Then, the emulsion was pasteurized at $65^{\circ} \mathrm{C}$ for $30 \mathrm{~min}$. After the pasteurization process, salad dressing samples were poured into brown bottles and cooled to room temperature. All material in this experiment was sterilized at $121^{\circ} \mathrm{C}$ for $15 \mathrm{~min}$.

\section{Physicochemical properties of the salad dressing samples}

The percentage acidity values of the extracts were determined according to International Union of Pure and Applied Chemistry (Dieffenbacher \& Pocklington, 1987). The color values of $\mathrm{L}^{*}$ (lightness/darkness), $\mathrm{a}^{*}$ (redness/greenness), and $\mathrm{b}^{*}$ (jaundice/ blueness) of salad dressing samples were determined with a color measuring device (CR-400 Konica, Minolta, Tokyo, Japan). The color measurement was carried out with three parallels. The averages and standard deviations of the obtained values were recorded. The $\mathrm{pH}$ of the salad dressing samples was measured with a pH meter at room temperature (WTWInolab, Weilheim, Germany). The $\mathrm{pH}$ meter probe was directly immersed in the samples. Three different measurements were conducted for each sample, and the mean values and standard deviations were expressed.

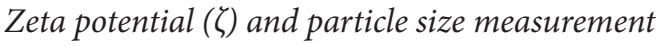

The oil particle size dispersed in the continuous phase of the salad dressing samples was determined with a zeta $(\zeta-)$ potential and particle size meter (Nanosizer, Malvern Instruments, Worcestershire, UK) with electrophoresis and dynamic light scattering system. The samples were diluted 100 times with ultrapure water and then homogenized by mixing in an ultrasonic water bath before the measurement. This procedure was repeated in triplicate for each sample by using the Zeta potential measurement, and the averages of the values and the standard deviation were calculated.

\section{Oxidative stability analysis}

The oxidative stability of the salad dressing samples was tested using the OXITEST Device (Velp Scientifica, Usmate, $\mathrm{MB}$, Italy). The $20 \mathrm{~g}$ of salad dressing was weighed into the sample cells, for example, uniform distribution was taken into consideration. The device temperature was set at 90, 100, and $110^{\circ} \mathrm{C}$, and the oxygen pressure was set at 6 bar. The oxidative stability values of the samples were interpreted based on the induction period (IP) value recorded by the OXITEST device. The instrument records the absolute oxygen pressure drop inside the instrument chambers, monitoring the oxygen-consuming by reactive components in the sample and automatically calculated an IP value from the oxidation curve by the graphical method. Another advantage of OXITEST devices is to extrapolate and estimate the oxidation stability of samples at room temperature, in the case of linear dependence with the temperature. From the OXISoft $^{\text {six }}$ program the shelf life of the salad dressing samples at room temperature was calculated.

By using the obtained data from the OXITEST devices, the equations of zero, first and second-order oxidation kinetics were calculated for different temperature values. For this purpose, nonlinear regression analysis was used to performed oxidation kinetics of the salad dressing. The pressure value corresponding to time were fitted to zero, first and second-order kinetic equation nonlinear regression analyasis calculated kinetic parameters using Statistica (StatSoft, Tulsa, USA).

The equations used in oxidation kinetic parameters were shown in Table 1 . In these equations, $\mathrm{C}_{0}$ represents the initial pressure value (bar) in the sample vessel of the Oxytest Device, $\mathrm{k}$ introduces the rate constant for oxidation kinetics, $\mathrm{C}$ represents the amount of pressure that varies with time, and time is defined as $t$ in hours.

The Arrhenius equation was used to determine the effect of temperature on the oxidation rate constant $(\mathrm{k})$ :

$k=A_{0} \times \exp \left(\frac{-E_{a}}{R T}\right)$

In the Equation 2, $\mathrm{E}_{\mathrm{a}}$ represents the activation energy $(\mathrm{kJ} / \mathrm{mol}), \mathrm{R}$ shows the ideal gas constant $(8,314 \mathrm{~J} / \mathrm{mol} / \mathrm{K})$, and the temperature is defined as T in $\mathrm{K}$. Activation enthalpy $\left(\Delta \mathrm{H}^{++}\right)$, and entropy $\left(\Delta S^{++}\right)$values were calculated using the equation derived from the activated complex theory (Equation 3):

$k=\frac{k_{B} t}{h} \exp \left(-\frac{\Delta H^{++}}{R T}+\frac{\Delta S^{++}}{R}\right)$

In this equation, $\mathrm{k}_{\mathrm{B}}$ is the Boltzmann constant $\left(1.3806488 \times 10^{-23} \mathrm{~J} / \mathrm{K}\right), \mathrm{h}$ is the Plank constant $\left(6.6261 \times 10^{-34} \mathrm{~J} / \mathrm{s}\right)$, $\mathrm{T}$ is the absolute temperature $(\mathrm{K}), \mathrm{R}$ is the ideal gas constant $(8.314 \mathrm{~J} / \mathrm{mol} / \mathrm{K}),\left(\Delta \mathrm{H}^{++}\right)$is the change in enthalpy $(\mathrm{kJ} / \mathrm{mol})$ and $\left(\Delta \mathrm{S}^{++}\right)$is the entropy change $(\mathrm{J} / \mathrm{mol} / \mathrm{K})$. Thanks to these equations, the relevant parameters were calculated using the nonlinear regression model. Statistica program (StatSoft, Tulsa, USA) was used for nonlinear regression.

Table 1. Equations used for oxidation kinetic of zero-, first-, and second-order models.

\begin{tabular}{ccc}
\hline Zero-order & First-order & Second-order \\
\hline Eq1: $C=C_{0}-k_{0} t$ & Eq2: $C=C_{0} \exp (-k t)$ & Eq3: $\frac{1}{C}=\frac{1}{C_{0}}+k t$ \\
\hline
\end{tabular}




\section{Statistical analysis}

The difference between the samples was analyzed by twofactor analysis. A Duncan multiple comparison tests were used to compare the samples, and the difference between the samples was determined at a confidence interval of 0.05. Statistical analyses were performed using Statistica (StatSoft, Tulsa, USA) as a statistical program. The mean and standard deviation were presented.

\section{Results and discussion}

\subsection{Total phenolic content, antioxidant capacity, and phenolic characterization of PGOB and GOB}

The total phenolic content of the extract was found to be $2959.10 \mathrm{mg} / \mathrm{kg}$ for PGOB and $3737.38 \mathrm{mg} / \mathrm{kg}$ for GOB. The antioxidant capacity of the samples was determined by the DPPH method and found to be $99 \%$ and $66 \%$ for GOB and PGOB, respectively. The results suggested that $\mathrm{PGOB}$ and GOB had the potential use of natural antioxidants. In addition to the

Table 2. The phenolic composition of POB and GOB extracts.

\begin{tabular}{crr}
\hline Compounds & GOB $(\mathrm{mg} / \mathrm{L})$ & PGOB $(\mathrm{mg} / \mathrm{L})$ \\
\hline gallic acid & $8.3 \pm 0.0^{\mathrm{b}}$ & $12.6 \pm 0.6^{\mathrm{a}}$ \\
gallocatechin & $342.6 \pm 1.7^{\mathrm{b}}$ & $989.6 \pm 3.8^{\mathrm{a}}$ \\
epigallocatechin & $116.6 \pm 0.9^{\mathrm{b}}$ & $1227.8 \pm 5.1^{\mathrm{a}}$ \\
catechin & $25.5 \pm 1.7^{\mathrm{a}}$ & $9.3 \pm 0.4^{\mathrm{b}}$ \\
chlorogenic acid & $21.5 \pm 0.3^{\mathrm{a}}$ & $20.0 \pm 1.3^{\mathrm{a}}$ \\
epicatechin & $1148.3 \pm 8.3^{\mathrm{a}}$ & $307.6 \pm 1.7^{\mathrm{b}}$ \\
p-coumaric acid & $996.9 \pm 2.2^{\mathrm{a}}$ & $38.5 \pm 1.0^{\mathrm{b}}$ \\
quercetin & $855.6 \pm 3.1^{\mathrm{a}}$ & $24.9 \pm 0.8^{\mathrm{b}}$ \\
resveratrol & $12.5 \pm 0.4^{\mathrm{a}}$ & $12.2 \pm 0.5^{\mathrm{a}}$ \\
catechin gallate & $21.1 \pm 0.6^{\mathrm{a}}$ & $1.8 \pm 0.2^{\mathrm{b}}$ \\
quercetin hydrate & $6.7 \pm 0.2^{\mathrm{b}}$ & $11.2 \pm 0.6^{\mathrm{a}}$ \\
kaempferol & $33.0 \pm 1.4^{\mathrm{b}}$ & $51.3 \pm 2.6^{\mathrm{a}}$ \\
\hline
\end{tabular}

GOB: Grape seed oil by-product; PGOB: Pomegranate seed oil by-product. Different lowercase letters in some row indicates statistical differences between samples subjected to a different temperature $(\mathrm{P}<0.05)$.
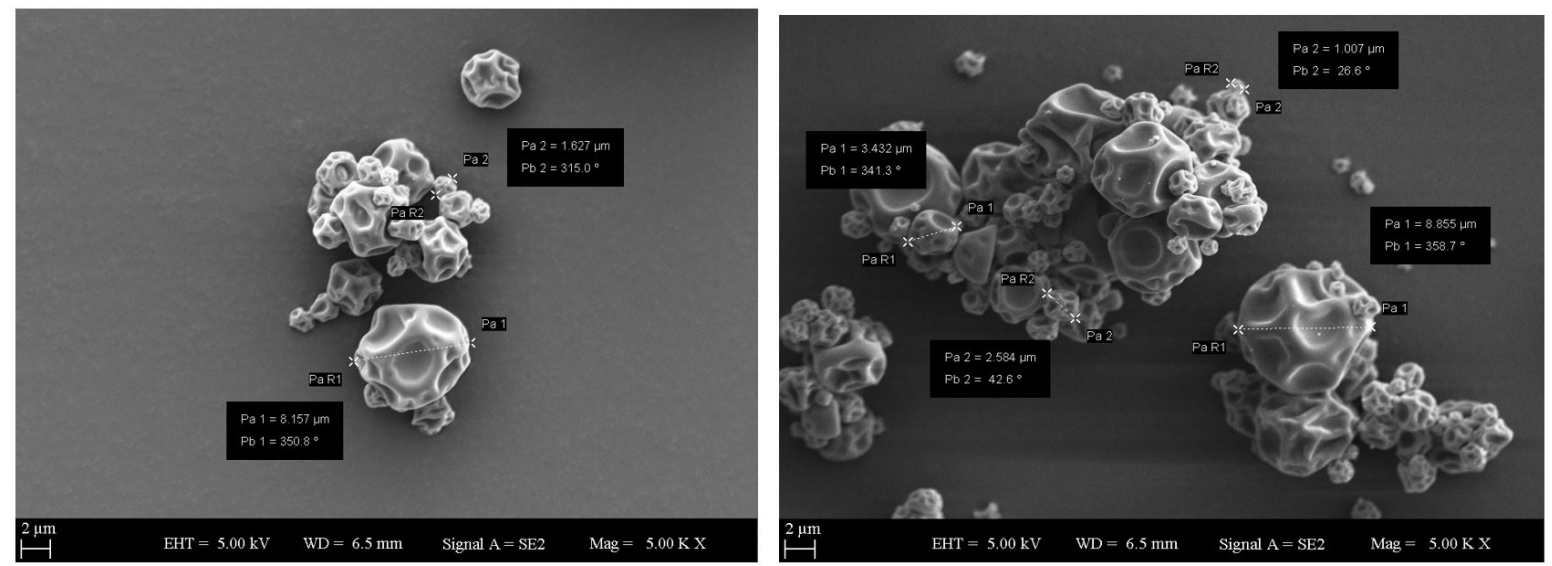

Figure 1. SEM images of the encapsulated phenolic extract. total phenolic content, the individual phenolic content of the samples was also be determined. Table 2 showed the individual phenolic contents of the PGOB and GOB. Individual phenolic contents were different according to by-products.

Epicatechin and epigallocatechin were determined as a major phenolic compound for the GOB and $\mathrm{PGOB}$ respectively. p-Coumaric acid and quercetin were other abundant phenolic compounds found in GOB. Gallocatechin was other major phenolic compounds determined in PGOB. Catechin, Gallic acid, and Epicatechin were also reported as the major phenolic compounds in grape seed from other studies (Mirbagheri et al., 2018; Peixoto et al., 2018). The antioxidant, cytotoxic and antibacterial activities of the methanol/water extracts prepared from grape pomace including grape seed have been studied by some authors (Cheng et al., 2012; Poveda et al., 2018). It was reported in these studies that the seed extracts of the grape pomace showed high antioxidant activity. Bioactive properties of the GOB and PGOB from the juices industry was studied by Durante et al. (2017). In their study, the total phenol content of the grape juice by-product was higher in our study. This result can be explained by the different grapes varieties used in our studies. The findings of this study and the results of other researchers suggested that GOB and PGOB could be utilized as a good antioxidant source.

\subsection{Powder characterization of GOBP and PGOBP extract}

Encapsulation of the GOB and PGOB extract was performed by spray drying at $180{ }^{\circ} \mathrm{C}$ with $3 \%$ maltodextrin (MD). MD microcapsules show a spherical shape and uniform distribution with no cracks or holes (Figure 1).

The particle diameters of the MD capsules ranged from 1.007 to $8.855 \mu \mathrm{m}$. The particles with pores or cracks were not observed, an indication that the encapsulation process was successfully performed, and phenolic compounds in the capsules can be preserved. Similar particle size and surface morphology were reported from previously published studies related to anthocyanin encapsulation by MD (Akhavan Mahdavi et al., 2016; Begum \& Deka, 2017). 


\subsection{Physicochemical properties of the salad dressing samples}

The physicochemical properties of the salad dressing samples prepared by the control sample, PGOB, and GOB containing samples were shown in Table 3 . The percentage acidity and $\mathrm{pH}$ value of the samples were found to be 4.81-4.85 and 1.08-1.41. The acidity value of the control samples was lower than the samples containing PGOBP and GOBP, respectively. $L^{*}, a^{*}$ and $b^{*}$ value of the samples were $86.80-91,(-2.32)-(-2.25)$ and 2.05-2.43. Higher $\mathrm{L}^{*}$ value for the samples containing PGOBP and GOBP can be explained by maltodextrin content as a wall material for the encapsulation of the PGOB and GOB extract.

$\zeta$-potential value of the samples varied from 18.06-27.56. Samples containing GOBP showed lower $\zeta$-potential than control samples. $\zeta$-potential is one of the most important parameters affecting the physical stability of salad dressing like emulsions. A higher the absolute magnitude of $\zeta$-potential value is desired due to causing electrostatic repulsion between droplets higher emulsion stability during storage (Dickinson, 2009). A high $\zeta$-potential value is highly related to components used in emulsion formulation. Therefore, when improving the antioxidant properties of emulsion products such as salad dressing, the potential value of the products should be taken into account.

In our study, compared to control samples, PGOBP did not reduce $\zeta$-potential while GOBP reduces from 27.56 to 18.06. The results from our work show that PGOBP can be conveniently used as an antioxidant source in salad dressings without causing any adverse effects on the physical stability of the product. The decline in $\zeta$-potential of the salad dressing a sample prepared with GOBP is within acceptable limits since no phase separation was observed during storage.

\subsection{Oxidation kinetics of the salad dressing samples}

Table 4 shows the IP values of the salad dressing samples. The IP values of the control, PGOBP, and GOBP containing

Table 3. The physicochemical properties of the salad dressing samples.

\begin{tabular}{|c|c|c|c|}
\hline Physicochemical Properties & Control & GOBP & PGOBP \\
\hline $\mathrm{pH}$ & $4.83 \pm 0.0^{\mathrm{a}}$ & $4.81 \pm 0.0^{\mathrm{a}}$ & $4.85 \pm 0.0^{\mathrm{a}}$ \\
\hline Acidity (\%) & $1.08 \pm 0.0^{\mathrm{b}}$ & $1.41 \pm 0.0^{\mathrm{a}}$ & $1.41 \pm 0.1^{\mathrm{a}}$ \\
\hline $\mathbf{L}^{*}$ & $86.8 \pm 0.3^{\mathrm{b}}$ & $91.0 \pm 0.4^{\mathrm{a}}$ & $90.7 \pm 0.4^{\mathrm{a}}$ \\
\hline $\mathbf{b}^{*}$ & $2.43 \pm 0.3^{\mathrm{a}}$ & $2.05 \pm 0.2^{\mathrm{c}}$ & $2.20 \pm 0.3^{\mathrm{b}}$ \\
\hline$\zeta$-potential $(\mathrm{mV})$ & $-27.6 \pm 0.9^{\mathrm{a}}$ & $-18.1 \pm 0.5^{\mathrm{b}}$ & $-25.5 \pm 1.4^{\mathrm{a}}$ \\
\hline Particle diameter (nm) & $329.8 \pm 35.3^{\mathrm{b}}$ & $748.9 \pm 60.1^{\mathrm{a}}$ & $404.7 \pm 172.9^{\mathrm{b}}$ \\
\hline
\end{tabular}

GOBP: Grape seed oil by-product powder; PGOBP: Pomegranate seed oil by-product powder. Different lowercase letter in the same row indicates effects of temperature on the physicochemical properties of the salad dressing samples $(\mathrm{P}<0.05)$.

Table 4. The oxidation kinetic parameters of the salad dressing samples.

\begin{tabular}{|c|c|c|c|c|c|c|c|c|c|c|}
\hline \multirow{3}{*}{ Temperature $\left({ }^{\circ} \mathrm{C}\right)$} & \multirow{3}{*}{$\mathrm{IP} / \mathrm{h}$} & \multicolumn{3}{|c|}{ Zero order } & \multicolumn{3}{|c|}{ First order } & \multicolumn{3}{|c|}{ Second order } \\
\hline & & \multicolumn{3}{|c|}{$\mathrm{Eq} 1: C=C_{0}-k_{0} t$} & \multicolumn{3}{|c|}{ Eq2: $C=C_{0} \exp (-k t)$} & \multicolumn{3}{|c|}{ Eq3: $\frac{1}{C}=\frac{1}{C_{0}}+k t$} \\
\hline & & $\mathrm{C}_{\mathrm{o}}$ & $\mathrm{k}$ & $\mathrm{R}$ & $\mathrm{C}_{\mathrm{o}}$ & $\mathrm{k}$ & $\mathrm{R}$ & $\mathrm{C}_{\mathrm{o}}$ & $\mathrm{k}$ & $\mathrm{R}$ \\
\hline \multicolumn{11}{|l|}{ Control } \\
\hline 70 & $8.92 \pm 0.01^{\mathrm{aC}}$ & 6.20 & $1.50^{\mathrm{eA}}$ & 0.955 & 6.25 & $0.369^{\mathrm{eA}}$ & 0.959 & 6.20 & $0.115^{\mathrm{eA}}$ & 0.999 \\
\hline 80 & $5.25 \pm 0.02^{\mathrm{bC}}$ & 6.17 & $2.55^{\mathrm{dA}}$ & 0.995 & 6.05 & $0.543^{\mathrm{dA}}$ & 0.996 & 6.15 & $0.227^{\mathrm{dA}}$ & 0.955 \\
\hline 90 & $3.55 \pm 0.07^{\mathrm{cB}}$ & 6.24 & $4.88^{\mathrm{cA}}$ & 0.933 & 6.55 & $1.570^{\mathrm{cA}}$ & 0.977 & 6.37 & $0.394^{\mathrm{cA}}$ & 0.965 \\
\hline 100 & $1.13 \pm 0.01^{\mathrm{dB}}$ & 6.66 & $14.04^{\mathrm{bA}}$ & 0.941 & 6.42 & $3.963^{\mathrm{bA}}$ & 0.964 & 7.04 & $1.282^{\mathrm{bA}}$ & 0.955 \\
\hline 110 & $0.43 \pm 0.01^{\mathrm{eC}}$ & 6.35 & $24.11^{\mathrm{aA}}$ & 0.944 & 6.74 & $9.616^{\mathrm{aA}}$ & 0.988 & 6.62 & $3.358^{\mathrm{aA}}$ & 0.923 \\
\hline \multicolumn{11}{|l|}{ GOBP } \\
\hline 70 & $26.71 \pm 0.03^{\mathrm{aA}}$ & 6.17 & $0.85^{\mathrm{eB}}$ & 0.956 & 6.18 & $0.257^{\mathrm{eB}}$ & 0.955 & 6.05 & $0.044^{\mathrm{eC}}$ & 0.955 \\
\hline 80 & $19.58 \pm 0.65^{\mathrm{bA}}$ & 6.11 & $1.17^{\mathrm{dB}}$ & 0.979 & 6.50 & $0.497^{\mathrm{dB}}$ & 0.989 & 6.11 & $0.093^{\mathrm{dC}}$ & 0.999 \\
\hline 90 & $13.43 \pm 0.04^{\mathrm{cA}}$ & 6.10 & $3.25^{\mathrm{cB}}$ & 0.886 & 7.12 & $0.669^{c c}$ & 0.979 & 6.53 & $0.192^{\mathrm{cB}}$ & 0.985 \\
\hline 100 & $7.33 \pm 0.01^{\mathrm{dA}}$ & 6.76 & $6.37^{\mathrm{bB}}$ & 0.955 & 7.45 & $1.651^{\mathrm{bB}}$ & 0.964 & 6.68 & $0.379^{\mathrm{bB}}$ & 0.957 \\
\hline 110 & $3.22 \pm 0.02^{\mathrm{eA}}$ & 6.35 & $13.12^{\mathrm{aB}}$ & 0.967 & 7.01 & $2.934^{\mathrm{aB}}$ & 0.963 & 6.46 & $0.712^{\mathrm{aC}}$ & 0.955 \\
\hline \multicolumn{11}{|l|}{ PGOBP } \\
\hline 70 & $24.76 \pm 0.02^{\mathrm{aB}}$ & 6.16 & $0.95^{\mathrm{eB}}$ & 0.976 & 6.10 & $0.221^{\mathrm{eB}}$ & 0.999 & 6.05 & $0.066^{\mathrm{eB}}$ & 0.999 \\
\hline 80 & $18.20 \pm 0.21^{\mathrm{bB}}$ & 6.05 & $1.38^{\mathrm{dB}}$ & 0.999 & 6.76 & $0.511^{\mathrm{dB}}$ & 0.955 & 6.55 & $0.123^{\mathrm{dB}}$ & 0.977 \\
\hline 90 & $12.37 \pm 0.01^{\mathrm{cA}}$ & 6.92 & $3.53^{\mathrm{cB}}$ & 0.922 & 7.02 & $0.867^{\mathrm{cB}}$ & 0.948 & 6.43 & $0.192^{\mathrm{cB}}$ & 0.988 \\
\hline 100 & $7.37 \pm 0.05^{\mathrm{dA}}$ & 6.75 & $6.132^{\mathrm{bB}}$ & 0.961 & 7.34 & $1.536^{\mathrm{bB}}$ & 0.948 & 6.79 & $0.357^{\mathrm{bB}}$ & 0.936 \\
\hline 110 & $2.49 \pm 0.04^{\mathrm{eB}}$ & 6.51 & $12.34^{\mathrm{aB}}$ & 0.972 & 7.14 & $3.259^{\mathrm{aB}}$ & 0.968 & 6.58 & $0.741^{\mathrm{aB}}$ & 0.966 \\
\hline
\end{tabular}

GOBP: Grape seed oil by-product powder; PGOBP: Pomegranate seed oil by-product powder. Different lowercase letter in the same column indicates effects of temperature on IP and $\mathrm{k}$ value $(\mathrm{P}<0.05)$; Different uppercase letters in some column indicated statistical differences between control samples and enriched with $\mathrm{POBP}$ and $\mathrm{GOBP}(\mathrm{P}<0.05)$. 
Table 5. The activation energy and activated complex theory parameters.

\begin{tabular}{|c|c|c|c|c|c|c|c|c|c|c|c|c|c|}
\hline \multirow{2}{*}{ Sample } & \multicolumn{5}{|c|}{$t_{1 / 2}(h)$} & \multirow{2}{*}{$\mathrm{E}_{\mathrm{a}}(\mathrm{kJ} / \mathrm{mol})$} & \multirow{2}{*}{$\Delta \mathrm{H}^{++}(\mathrm{kJ} / \mathrm{mol})$} & \multirow{2}{*}{$\Delta \mathrm{S}^{++}(\mathrm{J} / \mathrm{mol} / \mathrm{K})$} & \multicolumn{5}{|c|}{$\Delta \mathrm{G}^{++}\left(\mathrm{kJ} \mathrm{mol}^{-1}\right)$} \\
\hline & $70^{\circ} \mathrm{C}$ & $80^{\circ} \mathrm{C}$ & $90^{\circ} \mathrm{C}$ & $100^{\circ} \mathrm{C}$ & $110^{\circ} \mathrm{C}$ & & & & $70^{\circ} \mathrm{C}$ & $80^{\circ} \mathrm{C}$ & $90^{\circ} \mathrm{C}$ & $100^{\circ} \mathrm{C}$ & $110^{\circ} \mathrm{C}$ \\
\hline Control & $1.88^{\mathrm{aC}}$ & $0.93^{\mathrm{bB}}$ & $0.44^{\mathrm{cC}}$ & $0.17^{\mathrm{dC}}$ & $0.07^{\mathrm{eC}}$ & $41.31^{\mathrm{B}}$ & $81.07^{\mathrm{A}}$ & $-18.36^{\mathrm{A}}$ & 87.4 & 87.5 & 87.7 & 87.9 & 88.1 \\
\hline GOBP & $6.48^{\mathrm{aA}}$ & $2.33^{\mathrm{bA}}$ & $1.04^{\mathrm{cA}}$ & $0.42^{\mathrm{dB}}$ & $0.07^{\mathrm{eC}}$ & $45.90^{\mathrm{A}}$ & $59.55^{\mathrm{C}}$ & $-83.37^{\mathrm{C}}$ & 88.1 & 88.9 & 89.8 & 90.6 & 91.5 \\
\hline POBP & $5.73^{\mathrm{aB}}$ & $2.23^{\mathrm{bA}}$ & $0.79^{\mathrm{cB}}$ & $0.45^{\mathrm{dA}}$ & $0.21^{\mathrm{eB}}$ & $45.28^{A}$ & $63.26^{\mathrm{B}}$ & $-74.03^{\text {B }}$ & 88.7 & 89.4 & 90.1 & 90.8 & 91.6 \\
\hline
\end{tabular}

GOBP: Pomegranate seed oil by-product powder; GOBP: Grape seed oil by-product powder. Different lowercase letters in some row indicates statistical differences between samples subjected to a different temperature $(\mathrm{P}<0.05)$; Different uppercase letters in some column indicated statistical differences between control samples and enriched with POBP and GOBP $(\mathrm{P}<0.05)$.

samples were $0.43-8.92 \mathrm{~h}, 2.49-24.76 \mathrm{~h}$, and $26.76 \mathrm{~h}$ respectively, indicating that the addition of PGOBP and GOBP, and temperature significantly affected IP value.

The IP values of the samples containing PGOBP and GOBP were higher than that of the control sample at all temperatures, indicating that PGOBP and GOBP significantly increased the oxidative stability of the salad dressing samples. The increase in the oxidative stability of salad dressings can be explained by the localization of the PGOB and GOB-derived phenolics at the oil-water interface. Interaction of the by-product phenolic with other antioxidant molecules may have improved antioxidant activity and caused higher IP value (Waraho et al., 2011).

Another originality of this study was to perform the kinetic study by using OXITEST data. For this aim, the zeroth, first and second-order equations are used to determine the oxidation rate of samples. Oxidation decay curves were fitted to these equations to obtain the oxidation rate constants ( $\mathrm{k}$ values). The $\mathrm{k}$ values of the samples are shown in Table 4 . As can be seen, all of the kinetic equations successfully modeled the oxidation kinetics of the samples at all temperature values $\left(\mathrm{R}^{2}>0.93\right)$. At all temperature values, the $k$ values of the samples containing PGOBP and GOBP were statistically lower than the $\mathrm{k}$ value of the control sample. Lower $\mathrm{k}$ value shows a lower oxidation rate under accelerating conditions. From this finding, the phenolic extracts slow down the oxidation rate of the samples.

The effect of temperature on the oxidation kinetics of the samples was modeled by nonlinear regression using Arrhenius and Eyring equations. Table 5 shows the Arrhenius and Activation of complex parameters. As can be seen, $\mathrm{t}_{1 / 2}, \mathrm{E}_{\mathrm{a}} \Delta \mathrm{H}^{++}, \Delta \mathrm{S}^{++}$, and $\Delta \mathrm{G}$ values significantly differed. The $\mathrm{E}_{\mathrm{a}}$ value indicates the minimum energy value required to start oxidation. $\mathrm{E}_{\mathrm{a}}$ value was calculated as $41.308,45.282$, and $45.901 \mathrm{~kJ} / \mathrm{mol}$ for control, PGOBP, and GOBP enriched samples respectively. It appears that the addition of PGOBP and GOBP significantly increased the $\mathrm{E}_{\mathrm{a}}$ values of the samples.

In previous work, Souza et al. (2004) reported that $\mathrm{E}_{\mathrm{a}}$ for oxidation sunflower oil increased by the addition of artificial antioxidants. In a similar study, Yeşilsu \& Özyurt (2019) determined that enriched by rosemary, thyme, and laurel extracts increased $\mathrm{E}_{\mathrm{a}}$ for the oxidation of the fish oil. However, Farhoosh (2018) reported that the antioxidant type showed a different effect on $\mathrm{E}_{\mathrm{a}}$ for the oxidation of the oil. For this reason, $\mathrm{E}_{\mathrm{a}}$ is not enough parameter to evaluate antioxidant performance and should be used with activation complex parameters. In this study, therefore
$\Delta \mathrm{H}^{++}, \Delta \mathrm{S}^{++}$and $\Delta \mathrm{G}^{++}$were calculated to determine the temperature dependence behavior of the oxidation of salad dressing samples.

$\Delta \mathrm{H}^{++}$and $\Delta \mathrm{S}^{++}$values of the salad dressing samples were 69.781-101.93 and (-55.55)-(-38.3) respectively. Similar $\Delta \mathrm{H}^{++}$ and $\Delta \mathrm{S}^{++}$values were reported from a previously published study conducted on edible oil oxidation kinetics (Farhoosh \& Hoseini-Yazdi, 2014; Farhoosh et al., 2008; Hashemi et al., 2016). As can be seen, the control samples showed positive $\Delta \mathrm{S}^{++}$value while samples enriched with PGOBP and GOBP showed negative $\Delta \mathrm{S}^{++}$value. The positive value of $\Delta \mathrm{H}^{++}$indicates that the activated complex formation has endothermic behavior. The strong negative value of $\Delta \mathrm{S}^{++}$shows that the activated complexes are more ordered than the reactants molecules, and fewer numbers of species in the activated complex state (Farhoosh et al., 2008). The higher positive value of $\Delta \mathrm{H}^{++}$and negative value of $\Delta \mathrm{S}^{++}$indicate that the rate of oxidation in emulsions and oils is slow. In this case, the strong negative value of $\Delta \mathrm{S}^{++}$value in PGOBP and GOBP added salad dressings suggests that the antioxidants obtained from the by-products reduce the oxidation rate in salad dressing. Reduction of the $\Delta \mathrm{S}^{++}$be the addition of antioxidants can be explained by the reduction of free radical concentration by their hydrogen donation and loss of rotational freedom in the transiently activated complex (Farhoosh \& Hoseini-Yazdi, 2014).

$\Delta \mathrm{G}^{++}$is the free energy of activation and is valuable tools to show quantitative information about the oxidation rate of edible oils. The higher value of $\Delta \mathrm{G}^{++}$indicates a slower oxidation rate and strong oxidation resistance. $\Delta \mathrm{G}^{++}$values of control, PGOBP, and GOBP enriched samples were 87.36-88.10 kJ/mol, $88.65-91.61 \mathrm{~kJ} / \mathrm{mol}$, and $88.14-91.48 \mathrm{~kJ} / \mathrm{mol}$ respectively. The addition of the GOBP and PGOBP significantly increased $\Delta \mathrm{G}^{++}$values, indicating that the oxidation rate decrease after the addition of by-product extract (Table 5). It should be explained by free radical scavenging activity properties of the phenolic antioxidant in GOBP and PGOBP. The findings of the kinetic parameters and IP values were in agreement with each other. This study suggested that OXITEST could be used as an accelerating test in an evaluating of the salad dressing.

\section{Conclusion}

Phenolic extract of GOB and PGOB were added to salad dressing formulation to investigate their possible use as a natural antioxidant. The phenolic extract of GOB and PGOB significantly increase IP and $\Delta \mathrm{G}^{++}$, and decrease $\Delta \mathrm{S}^{++}, \Delta \mathrm{H}^{++}$value. Oxidation stability of the salad dressing significantly increased after the addition of the GOB and PGOB extract without lowering physical 
stability. GOB and PGOB extract should be successfully used as a natural antioxidant agent for the salad dressing like emulsions. This study suggested that OXITEST can be successfully used in an evaluating of the oxidative stability of the salad dressing like emulsions.

\section{References}

Akcicek, A., \& Karasu, S. (2018). Utilization of cold pressed chia seed oil waste in a low-fat salad dressing as natural fat replacer. Journal of Food Process Engineering, 41(5), e12694. http://dx.doi.org/10.1111/ jfpe.12694.

Akhavan Mahdavi, S., Jafari, S. M., Assadpour, E., \& Ghorbani, M. (2016). Storage stability of encapsulated barberry's anthocyanin and its application in jelly formulation. Journal of Food Engineering, 181, 59-66. http://dx.doi.org/10.1016/j.jfoodeng.2016.03.003.

Amato, M., Caruso, M. C., Guzzo, F., Galgano, F., Commisso, M., Bochicchio, R., Labella, R., \& Favati, F. (2015). Nutritional quality of seeds and leaf metabolites of Chia (Salvia hispanica L.) from Southern Italy. European Food Research and Technology, 241(5), 615-625. http://dx.doi.org/10.1007/s00217-015-2488-9.

Anwar, F., Bhanger, M. I., \& Kazi, T. G. (2003). Relationship between rancimat and active oxygen method values at varying temperatures for several oils and fats. Journal of the American Oil Chemists' Society, 80(2), 151-155. http://dx.doi.org/10.1007/s11746-003-0668-2.

Aydeniz, B., Güneşer, O., \& Yllmaz, E. (2014). Physico-chemical, sensory and aromatic properties of cold press produced safflower oil. Journal of the American Oil Chemists' Society, 91(1), 99-110. http://dx.doi. org/10.1007/s11746-013-2355-4.

Begum, Y. A., \& Deka, S. C. (2017). Stability of spray-dried microencapsulated anthocyanins extracted from culinary banana bract. International Journal of Food Properties, 20(12), 3135-3148. http://dx.doi.org/10 $.1080 / 10942912.2016 .1277739$.

Caruso, M. C., Galgano, F., Colangelo, M. A., Condelli, N., Scarpa, T., Tolve, R., \& Favati, F. (2017). Evaluation of the oxidative stability of bakery products by OXITEST method and sensory analysis. European Food Research and Technology, 243(7), 1183-1191. http:// dx.doi.org/10.1007/s00217-016-2831-9.

Cheng, V. J., Bekhit, A. E.-D. A., McConnell, M., Mros, S., \& Zhao, J. (2012). Effect of extraction solvent, waste fraction and grape variety on the antimicrobial and antioxidant activities of extracts from wine residue from cool climate. Food Chemistry, 134(1), 474-482. http:// dx.doi.org/10.1016/j.foodchem.2012.02.103.

Dickinson, E. (2009). 2009/08/01/). Hydrocolloids as emulsifiers and emulsion stabilizers. Food Hydrocolloids, 23(6), 1473-1482. http:// dx.doi.org/10.1016/j.foodhyd.2008.08.005.

Dieffenbacher, A., \& Pocklington, W. D. (1987). Standard Methods for the Analysis of Oils, Fats and Derivatives. In: International Union of Pure and Applied Chemistry (7th ed.). Oxford: Blackwell Scientific.

Durante, M., Montefusco, A., Marrese, P. P., Soccio, M., Pastore, D., Piro, G., Mita, G., \& Lenucci, M. S. (2017). Seeds of pomegranate, tomato and grapes: An underestimated source of natural bioactive molecules and antioxidants from agri-food by-products. Journal of Food Composition and Analysis, 63, 65-72. http://dx.doi.org/10.1016/j. jfca.2017.07.026.

Farhoosh, R. (2018). A kinetic approach to evaluate the structure-based performance of antioxidants during lipid oxidation. Journal of Food Science, 83(1), 101-107. http://dx.doi.org/10.1111/1750-3841.13993. PMid:29210460.
Farhoosh, R., \& Hoseini-Yazdi, S. Z. (2014). Evolution of oxidative values during kinetic studies on olive oil oxidation in the rancimat test. Journal of the American Oil Chemists' Society, 91(2), 281-293. http://dx.doi.org/10.1007/s11746-013-2368-z.

Farhoosh, R., Niazmand, R., Rezaei, M., \& Sarabi, M. (2008). Kinetic parameter determination of vegetable oil oxidation under Rancimat test conditions. European Journal of Lipid Science and Technology, 110(6), 587-592. http://dx.doi.org/10.1002/ejlt.200800004.

Ghorbani Gorji, S., Smyth, H. E., Sharma, M., \& Fitzgerald, M. (2016). Lipid oxidation in mayonnaise and the role of natural antioxidants: a review. Trends in Food Science \& Technology, 56, 88-102. http:// dx.doi.org/10.1016/j.tifs.2016.08.002.

Hashemi, S. M. B., Brewer, M. S., Safari, J., Nowroozi, M., Abadi Sherahi, M. H., Sadeghi, B., \& Ghafoori, M. (2016). 2016/02/01). Antioxidant activity, reaction mechanisms, and kinetics of matricaria recutita extract in commercial blended oil oxidation. International Journal of Food Properties, 19(2), 257-271. http://dx.doi.org/10.1080/1094 2912.2015.1020438.

Karaman, S., Karasu, S., Tornuk, F., Toker, O. S., Geçgel, Ü., Sagdic, O., Ozcan, N., \& Gül, O. (2015). Recovery potential of cold press byproducts obtained from the edible oil industry: physicochemical, bioactive, and antimicrobial properties. Journal of Agricultural and Food Chemistry, 63(8), 2305-2313. http://dx.doi.org/10.1021/ jf504390t. PMid:25647068.

Mirbagheri, V., Alizadeh, E., Yousef Elahi, M., \& Esmaeilzadeh Bahabadi, S. (2018). Phenolic content and antioxidant properties of seeds from different grape cultivars grown in Iran. Natural Product Research, 32(4), 425-429. http://dx.doi.org/10.1080/14786419.2017.130670 5. PMid:28391711.

Patrizia, C., Vito, V., Paola, M., \& Fiorenza, C. M. (2009). Accelerated oxidation: comparative study of a new reactor with oxidation stability instrument. European Journal of Lipid Science and Technology, 111(9), 933-940. http://dx.doi.org/10.1002/ejlt.200900009.

Peixoto, C. M., Dias, M. I., Alves, M. J., Calhelha, R. C., Barros, L., Pinho, S. P., \& Ferreira, I. C. F. R. (2018). Grape pomace as a source of phenolic compounds and diverse bioactive properties. Food Chemistry, 253, 132-138. http://dx.doi.org/10.1016/j.foodchem.2018.01.163. PMid:29502813.

Poveda, J. M., Loarce, L., Alarcón, M., Díaz-Maroto, M. C., \& Alañón, M. E. (2018). Revalorization of winery by-products as source of natural preservatives obtained by means of green extraction techniques. Industrial Crops and Products, 112, 617-625. http:// dx.doi.org/10.1016/j.indcrop.2017.12.063.

Prior, R. L., Wu, X., \& Schaich, K. (2005). Standardized methods for the determination of antioxidant capacity and phenolics in foods and dietary supplements. Journal of Agricultural and Food Chemistry, 53(10), 4290-4302. http://dx.doi.org/10.1021/jf0502698. PMid:15884874.

Shinagawa, F. B., Santana, F. C., Torres, L. R. O., \& Mancini-Filho, J. (2015). Grape seed oil: a potential functional food? Food Science and Technology, 35(3), 399-406. http://dx.doi.org/10.1590/1678-457X.6826.

Singleton, V. L., \& Rossi, J. A. (1965). Colorimetry of total phenolics with phosphomolybdic-phosphotungstic acid reagents. American Journal of Enology and Viticulture, 16(3), 144-158. Retrieved from http://www.ajevonline.org/content/ajev/16/3/144.full.pdf

Souza, A. G., Santos, J. C. O., Conceição, M. M., Silva, M. C. D., \& Prasad, S. (2004). A thermoanalytic and kinetic study of sunflower oil. Brazilian Journal of Chemical Engineering, 21(2), 265-273. http:// dx.doi.org/10.1590/S0104-66322004000200017.

Tinello, F., Lante, A., Bernardi, M., Cappiello, F., Galgano, F., Caruso, M. C., \& Favati, F. (2018). Comparison of OXITEST and RANCIMAT 
methods to evaluate the oxidative stability in frying oils. European Food Research and Technology, 244(4), 747-755. http://dx.doi. org/10.1007/s00217-017-2995-y.

Wang, R. F., Xie, W. D., Zhang, Z., Xing, D. M., Ding, Y., Wang, W., Ma, C., \& Du, L. J. (2004). Bioactive compounds from the seeds of Punica granatum (pomegranate). Journal of Natural Products, 67(12), 2096-2098. http://dx.doi.org/10.1021/np0498051. PMid:15620261.

Waraho, T., McClements, D. J., \& Decker, E. A. (2011). Mechanisms of lipid oxidation in food dispersions. Trends in Food Science \& Technology, 22(1), 3-13. http://dx.doi.org/10.1016/j.tifs.2010.11.003.
Yeșilsu, A. F., \& Özyurt, G. (2019). Oxidative stability of microencapsulated fish oil with rosemary, thyme and laurel extracts: a kinetic assessment. Journal of Food Engineering, 240, 171-182. http://dx.doi.org/10.1016/j. jfoodeng.2018.07.021.

Yoshime, L. T., Melo, I. L. P., Sattler, J. A. G., Torres, R. P., \& Mancini-Filho, J. (2019). Bioactive compounds and the antioxidant capacities of seed oils from pomegranate (Punica granatum L.) and bitter gourd (Momordica charantia L.). Food Science and Technology, 39(Suppl. 2), 571-580. http://dx.doi. org/10.1590/fst.23218. 